\title{
Estimating and Quantifying the Production Outcomes and Lifestyle Changes for Small-to Medium Sized Dairy Farms When Transitioning From Conventional to Automatic Milking Systems in the Northeast Region: A Case Study Report
}

\author{
Kasey M Moyes*, Li Ma, Dale Johnson, Stan Fultz and Robert R Peters \\ Department of Animal and Avian Sciences, University of Maryland, Washington DC, USA
}

Received: December 15, 2017; Published: December 19, 2017

*Corresponding author: Kasey M. Moyes, Department of Animal and Avian Sciences, College Park, University of Maryland, Washington DC, USA

\section{Introduction}

Primary reasons for lack of expansion of small to mediumsized dairies in the Mid-Atlantic region are the high cost of land, low profits, and labor availability. As herd size continues to increase globally, new technology allowing farmers to remain sustainable is greatly desired. Automatic milking systems (AMS) represent the most recent technology available by offering improved management and production efficiency, quality of life and attractiveness to successors. However, the financial investment is substantial. Although there is growing data on production impacts for European farmers, this technology is fairly new to the U.S. In turn, U.S. farmers lack information from independent sources regarding return on production performance and animal health associated with the transition from conventional to AMS for U.S. dairy operations. Results from a survey to dairy farmers in the Mid-Atlantic region of the U.S. reported that improving herd management and personal flexibility were some of the most important factors regarding their interest in AMS Moyes et al. [1]. Only $18.0 \%$ of farmers said they have access to information regarding changes in animal health and personal flexibility. Producers stated that more information on animal health and personal flexibility would be helpful when considering a transition to AMS. The objective of this study was to estimate and quantify the animal health, productivity and lifestyle changes for small-to medium sized dairy farms regarding the transition from conventional to AMS in the Mid-Atlantic region. Economic impact (including cash flow and labor) is not reported here.

\section{Materials and Methods}

Four dairy herds ( $\mathrm{n}=286 \pm 154$ milking cows/herd) in the midAtlantic region were used for this study. A general survey, including geographics, herd management and personal time commitments, for each farm was conducted before and after their transition to
AMS. Monthly herd summaries using data from two years relative to transition were used from either the dairy herd improvement association (DHIA) or Ag Source Cooperative services to generate monthly average herd production, reproduction, disease, and culling information (i.e. cull rate and reasons culled) where treatment was either conventional (CON; before transition) or automatic (AMS; after transition) milking systems. All numeric data was analyzed by herds using the PROC MIXED procedure of SAS (SAS/STAT version 9.3; SAS Institute Inc., Cary, NC).

\section{Results and Discussion}

Results from the survey indicated that all cows fully transitioned to AMS within a few weeks. One herd was pasture-based whereas all other herds $(n=3)$ were housed in free stalls with access to a partial mixed ration. One herd did not continue with the monthly DHIA service and therefore results were not used. Herds implemented either the De Laval, Lely or Galaxy-Astrea robots. This decision was primarily based on the location of the dealer service. For all herds, fresh and sick cows where milked using the conventional parlors. Producers observed improved personal flexibility transitioning to AMS (as measured by family and vacation time). Daily robot maintenance was minimal ( $\sim 1$ hour/day). No change in herd size or cull rate was observed. Regarding reproductive traits, calving interval (12.9 $\pm 0.15 \mathrm{CON} ; 13.13 \pm 0.18$ months AMS) and number of days open ( $121 \pm 6.0 \mathrm{CON}$; $128 \pm 5.0$ days AMS) increased for AMS than CON and maybe partly attributed to more naturally occurring heat detection methods for AMS than CON. Regarding animal health, the reasons for culling shifted towards low milk production being the main reason animals were removed from the herd.

There was no change observed regarding the monthly milk SCC as increases in milk yield were observed when producers transitioned to AMS (Table 1). Milk yield increased in all herds 
and is most likely attributed to an increase milking frequency that is commonly observed when transitioning to AMS. In conclusion, producers were happy with their decision to transition primarily via the labor reduction (not reported here) and improved personal time. Daily maintenance of robots is minimal. Cull rate does not seem to be impacted when transitioning to AMS. Milk yield, calving interval and days open increased for AMS when compared to CON.

Table 1: Monthly milk somatic cell count $\left(\mathrm{SCC}_{1}\right)$ and milk yield for herds that transitioned to automatic milking systems $(\mathrm{AMS} ; \pm 2$ years relative to transition).

\begin{tabular}{|c|c|c|c|c|c|c|}
\hline \multirow[b]{2}{*}{ Herd } & \multicolumn{3}{|c|}{ Milk Yield } & \multicolumn{3}{|c|}{ SCC } \\
\hline & P-value & $\mathrm{CON}^{2}$ & AMS & P-value & & After AMS \\
\hline 13 & - & $74.7 \pm 0.7$ & - & - & $157.7 \pm 11$ & - \\
\hline 2 & $<0.001$ & $67.7 \pm 0.7$ & $72.1 \pm 0.9$ & 0.87 & $170.2 \pm 14$ & $173.9 \pm 0.2$ \\
\hline 3 & 0.008 & $78.2 \pm 0.7$ & $80.5 \pm 0.7$ & 0.30 & $161.9 \pm 10$ & $146.3 \pm 10$ \\
\hline 4 & $<0.001$ & $71.7 \pm 0.9$ & $78.0 \pm 0.9$ & 0.64 & $256.6 \pm 19$ & $269.4 \pm 19$ \\
\hline
\end{tabular}

a) $\quad 15 C C$ based on weighted averages. Data reported as SCC $/ \mu \mathrm{L}$.

b) $\quad 2 \mathrm{CON}=$ conventional milking system.

c) 3 No after AMS data available for this herd.

\section{References}

1. Moyes KM, Ma L, McCoy TK, Peters RR (2014) A survey regarding the interest and concerns associated with transitioning from conventional to automated (robotic) milking systems for managers of small to mediumsized dairy farms. Prof Anim Sci 30(4): 418-422.
Animal health (based on SCC)did not change for all herds enrolled but previous research indicates clinical mastitis can improve when producers transition to AMS Tse et al. [2]. Automated milking systems may improve animal productivity and lifestyle changes but AMS may not impact animal health or reproduction for small-to medium sized dairy farms in the Northeastern region.
2. Tse C, Barkema HW, DeVries TJ, Rushen J, Pajor EA (2017) Effect of transitioning to automatic milking systems on producers' perceptions of farm management and cow health in the Canadian dairy industry. J Dairy Sci 100(3): 2404-2414.

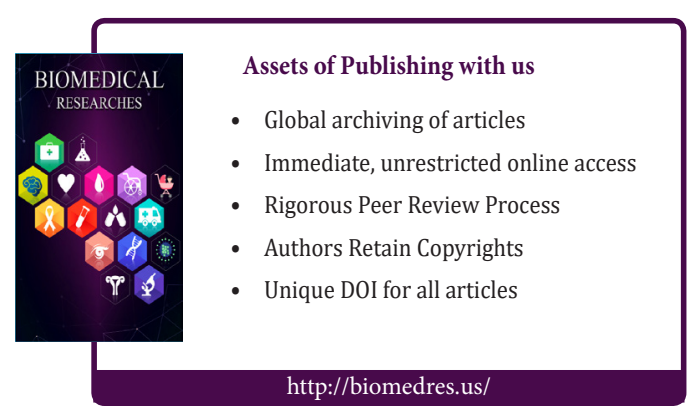

